\title{
The Determinants and Outcomes of Supplier Satisfaction
}

\author{
Saleem Ahmed, Muhammad Asim, and Salman Manzoor
}

\begin{abstract}
The study aims to evaluate how the supplier commitment, supplier attractiveness, supplier satisfaction and supplier trust are influenced by service quality, communication quality and time management quality. 157 responses were collected from the target population consisting of manufacturing firms of Karachi. Sampling technique included the purposive sampling technique and data was analyzed using PLS-SEM. The study found that supplier satisfaction was positively and significantly impacting supplier attraction, supplier commitment and supplier trust while it was also positively and significantly impacted by communication quality, service quality and time management quality. The study has several recommendations for the managers on the basis of the results of the data analysis. The managers are recommended to focus on the various antecedents of quality as they help in enhancing the supplier satisfaction as the study also found that supplier satisfaction was essential in improving the supplier attractiveness, supplier trust and supplier commitment. By improving the communication, service and time management quality, the manufacturing firms can significantly boost their relationship with the suppliers and enhance their performance.
\end{abstract}

Keywords-Supplier commitment, supplier trust, supplier attractiveness, supplier satisfaction, quality.

\section{INTRODUCTION}

The role of supply chain in a manufacturing firm is developing because it led to have improved level of relationship with the supply chain. So, as in [35] stated that the different type of relationship with the suppliers contributed to competitive advantage of the firms and the one aspect that improved a lot was supplier performance. Also, as in [33] proposed that those firms that have better and quality supplier performance and enhanced access to the resources of supplier were having huge management and communication quality with an increased advantage. More importantly, it was found in as in [16] that supplier was highly showed willingness and agreeableness to give beneficial treatment to such firms that had enhanced level of satisfaction, commitment and trust with them as in [2]. However, this information opened up a discussion that in what manner and a firm can enhance supplier satisfaction for receiving and achieving some preferential services. Furthermore, it was proposed that the function of procurement played a connection link among the firm and the supplier as in [22]. Therefore, by implanting this process procurement could influence the suppliers for achieving high supplier performance. In addition, as in [5] stated that the supplier satisfaction was enhanced using communication and service quality in such a way that having high service quality helped in production. Similarly, it was found that high satisfaction level of suppliers helped in such way that suppliers were feeling more committed and attracted towards the firms as in [1].

Additionally, previous researches and publications showed the process that in what manner the variables; supplier attractiveness and satisfaction of suppliers could highly contribute towards the preferred customer status as in [30]. Although, various studies revealed and focused on the study of buyer-supplier alignment, trust, and commitment and the relation of these constructs with supplier satisfaction as in [38] as in [29]. Also, the antecedents of supplier satisfaction were not previously examined at a great length and different firms were found lacking in having high amount of satisfaction with suppliers and their development was affected by it as in [5]. However, factors of corporate image and policy regarding payment was highly examined in the aspect of supplier satisfaction as in [26]. Hence, it was showed that supplier satisfaction was not highly examined therefore the current study aimed to examine the aspect of supplier satisfaction and commitment, attractiveness and supplier trust as well.

The study will be of great significance for the academicians and the practitioners. The study aims to evaluate how the supplier commitment, supplier attractiveness and supplier trust are affected by various antecedents. These variables are measured with the help of service quality, communication quality and time management quality as the independent variables, supplier satisfaction as the mediating variable while the commitment, attractiveness and trust of the suppliers as the dependent variables. The academicians will be able to better understand how the relationship with the suppliers can be improved if the suppliers are satisfied by improving the service quality, communication quality and time management quality in context to the supply chain firms of Karachi, Pakistan. They will be provided with evidence regarding the effects on relationship with the suppliers in context to the quality and satisfaction of the supplier as well as the supply chain. The practitioners will also be provided beneficial findings regarding the topic where they will be able to understand how they can satisfy their suppliers and in return enhance their relationship with the suppliers in the Pakistani supply chain organizations.

The following is the organization of the research. The first section includes background regarding the topic as well as research problem and gap. The second section includes the literature reviews of previous studies and their findings. The third section discusses the research methods including the quantitative positivism, purposive sampling etc. The fourth chapter includes the data analysis and the findings of the analysis. The fifth section discusses the discussion 
about the findings. The sixth section discusses the conclusion that the study has reached.

\section{LITERATURE REVIEWS}

As in [27] used the method of two sided matching in the export of business to business across borders under the context of electronic trade on the basis of the stakeholders' satisfaction. The degree of satisfaction depends on different indicators that were identified in past studies. By using the interval and linguistic information of assessment, they developed a model and found that the quality of service along with other factors has significant impact on satisfaction of suppliers. Another study conducted by as in [3]. A qualitative research on the basis of case study to investigate the antecedents of supplier satisfaction. The analysis of the selected case study showed that there is a strong link between different antecedents like the quality of service with the satisfaction of suppliers. Thus we hypothesize that:

\section{H1. Service quality has significant effect on supplier} satisfaction.

There are different dimensions that describe satisfaction of the suppliers. Communication dimension is one of them. This dimension is the softer one that depends upon the human values. Such values are generated from the trust, openness and responsibilities. Thus as in [31] expanded the understandings related to satisfaction of suppliers focusing on the resource dependence theory. It was found in the study that the strong communication among the partners develop satisfaction for the suppliers. As in [13] also focused on the significance of external as well as internal factors of the organizations that have effect on their performance as well as on the satisfaction of their suppliers. By conducting a survey study with 185 small food industries, it was identified that the integration of information along with the communication quality has significant effects on satisfaction of suppliers. Thus we hypothesize that:

\section{H2. Communication quality has significant effect on} supplier satisfaction

The buying firms have to improve their attractiveness in order to gain higher satisfaction for its suppliers. Past studies on this relationship between buyer and supplier have provided different factors that bring success in this relationship. As in [36] also focused on the interacting factors that affect the buyer supplier relationship. They performed interview sessions with 43 sales persons and buyers. The analysis results showed that there are many different factors that affect satisfaction of buyers positively. One of them is the efficient management of time that would bring more quality to the product or service. As in [30] also conducted a study in this regard and revealed that the

quality time management by the vendors and customers attract more good relationship between the buyers and sellers and thus the suppliers get more satisfied. Thus we hypothesize that:

H3. Time management quality has significant effect on supplier satisfaction

It is getting important day by day for the buyers to gain an ideal status of customer that is not possible without having satisfaction for the suppliers. Thus as in [14] investigated the concepts related to supplier satisfaction and its further impacts. The research analysis showed that the supplier satisfaction brings significant impact on their commitment with the customers. Another study by as in [32] investigated the relationship between the supplier level satisfaction and the commitment of supplier in long run. For this study, they collected data from 159 producers of footwear through structured questionnaire. The multiple regression analysis provided support to the proposed hypotheses. It was found that there is a strong relationship between the supplier satisfaction and the long term commitment from suppliers. Further it was found that this relationship gets stronger with the passage of time. Another study by as in [28] worked on the associations between buyers and suppliers and their impact on the supplier related satisfaction. The authors conducted an international survey for this study and the collected data was studied through Structured Equation Model. It was confirmed through this analysis that the quality performance including effective time management brings positive effect on the supplier satisfaction. Thus we hypothesize that:

\section{H4. Supplier satisfaction has significant effect on supplier commitment.}

In a relationship between buyers and suppliers, both of the involved parties have target to continue the relationship to attain competitive advantage. As the development of this relationship is very time consuming as well as needs efforts, both parties are now conscious in terms of selecting the business partner. Thus both parties work on developing their attractiveness to develop a relationship. Thus as in [34] investigated the supplier related attractiveness in this association. They conducted interviews with 43 buyers and sellers. The analysis showed that the supplier attractiveness is strongly affected by the relationship and the related satisfaction. Since this concept of attractiveness has gain much more importance in the literature, many researchers have included this relationship in their studied models to discuss. Thus, as in [24] conducted a study claiming that the attractiveness of suppliers is related with their experience level and also with the business outcomes. Case studies were analyzed in this qualitative research and it was found that the adoptions as well as the attractiveness to suppliers are strongly related with the supplier satisfaction level with the relationship. Thus we hypothesize that:

\section{H5. Supplier satisfaction has significant effect on supplier attractiveness}

Any organization's purchasing department is a very important one that performs strategic functions and 
develops competitive advantage. For developing a competitive advantage, it is necessary to satisfy the related suppliers. The association between the commitment and trust has been studied before; however as in [37] conducted a study in order to investigate the relationship between supplier satisfaction and the supplier trust. The selected trust types in this study were the trust intention, trust belief and the commitments. For this study, they collected data from different organizations' suppliers and the collected data was studied through SPSS and PLS path modeling. The analysis results revealed that there is a strong relationship between the suppliers' satisfaction and supplier related trust. This study showed that the buying firms need to keep suppliers satisfied in order to develop trust. In the same context, as in [17] also investigated the association between supplier satisfaction and their related trust level in a relationship. The analysis results showed that supplier satisfaction is positively effective on the related trust levels. Thus we hypothesize that:

H6.

Supplier satisfaction has significant effect on supplier trust.

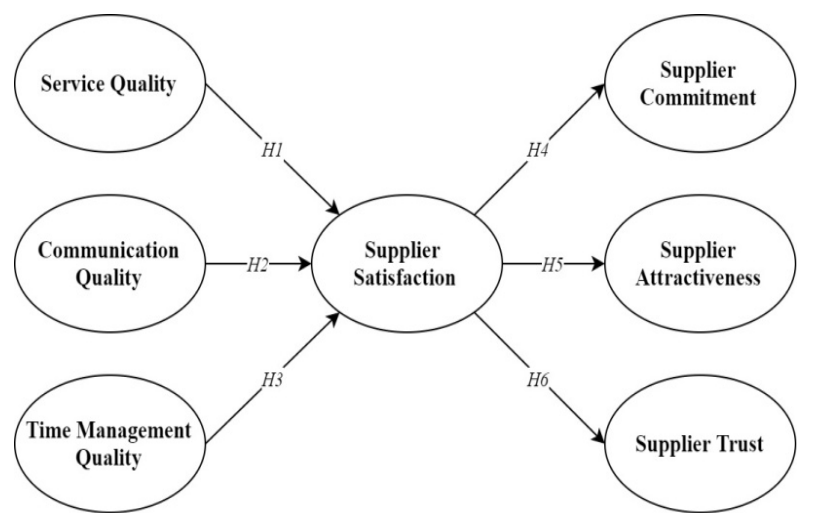

\section{METHODOLOGY}

The term positivistic philosophy is consisted of such information and the amount of knowledge that only belongs to the natural phenomena. In addition, it is also stated that the major perspective of positivistic is that it based on genuine and actual level of information and facts and highly neglects any false details. However, it could be said that it only involves the knowledge formation with the help of natural observation and different experiments [15].

Similarly, the research approach is based on two types that includes quantitative and qualitative. The natural and primary concept behind quantitative approach is that it provides the researchers for data collection an easy way

and this data is purely based on numerically values [6]. This approach can be used through collecting the data from surveys and questionnaires. In addition, another necessary element in conducting a research is research design and the highly essential one is correlation. It is totally based on examining such a study that is not highly and totally examined previously and it also demands priority. However, it helps in examining the relation between variables as in [7]. Hence, after reviewing these characteristics and advantages of quantitative approach and correlational design, the current study highly aimed to use these two methods. Though, the basic rational for selecting quantitative approach was that it allowed the researcher to conduct a broad study via using large amount of responses as in [18]. It also could help in the generalization of results and achieving quite high accuracy of the results as well. However, the correlational design was selected in order to examine a large model or such models which involved huge amount of variables. Similarly, it also helped in examining the relation and the degree of that relation that how much the variables are related and their directions as well that which variable affected the other in what manner as in [19]. Furthermore, collecting data is also another method in a research and there are many methods for this process. The highly used approach or method is five-point Likert scale that means the researcher has to collect data via developing questionnaires regarding the research problem and their objectives as in [20]. Additionally, the respondents that are the necessary and important part in a research are also selected using one of the sampling techniques. The role of purposive sampling is that it selects such people from target population which have necessary and required amount of knowledge about the research objective [21].

Moreover, the current study has chosen five-point Likert method and the purposive sampling for data collection. So, the reason for selecting Likert scale was that questionnaires development was relatively easier in managing and distributing and it was less costly as well. It also helped in gathering large quantity data from a huge population with more efficiency as in [23]. However, the rational of selecting purposive sampling was that it could help in selecting those persons that are close to the topic of research and could provide such information that enhanced the understanding of researchers as in [25].

The collected responses in this study were mainly from the supply chain professionals of manufacturing firms of Karachi, Pakistan while the estimation of sample size was based on N10 formula as in [10]. In addition, this study highly aimed to use PLS-SEM analysis for analyzing the data. So, the reasons for using this technique were that it was highly equipped or relevant in analyzing the statistical data and the complexity based models. In this technique the two models were structural and measurement [12]. The first model was highly useful in hypothesis testing and the role of later model was that it helped in statistical analysis [8].

\section{RESULTS AND FINDINGS}

\section{Profile of the Respondents}

The study has collected data from 11, 12, 68, and 66 supply chain professionals that were working in an organization with less than 50 employees, 50-200 employees, 200-500 employees and above 500 employees respectively. The 78 respondents provided that their major and core technology focus was communication/It industry, whereas 68 and 11 respondents provided that their major and core technology 
focus was logistics management and vehicles management correspondingly. Amongst total 157 respondents, 44 were assistant managers, 69 were managers, and 44 were senior managers; whereas 34 respondents having the experience of 1-5 years, 35 respondents have 5-10 years of professional experience and remaining 88 respondents have professional working experience of 10-15 years.

Measurement Model

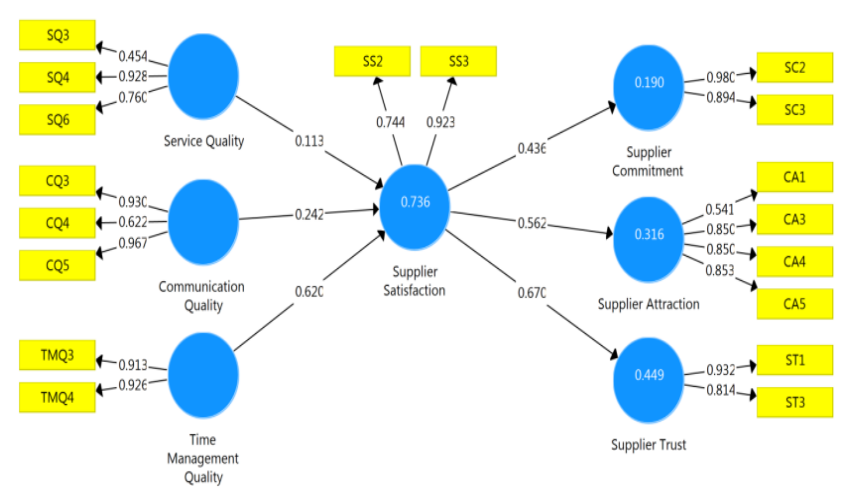

TABLE 1: FOLLOWING TABLE PROVIDES RESULT OF MEASUREMENT MODEL USING PLS ALGORITHM (SMARTPLS VERSION 3.2.8). of communication quality. However, the CR and AVE of service quality were 0.772 and 0.548 respectively; the CR and AVE of supplier attraction were 0.862 and 0.616 and lastly, the CR and AVE of communication quality was 0.886 and 0.729 . Therefore, measurement model have provided considerable results for further analysis.

TABLE 2: DISCRIMINANT VALIDITY USING FORNELL AND LARCKER (1981) CRITERION

\begin{tabular}{|c|c|c|c|c|c|c|c|}
\hline & CQ & SQ & SA & $\mathrm{SC}$ & SS & ST & TMQ \\
\hline Communication & 0.854 & & & & & & \\
\hline Quality & 0.466 & 0.741 & & & & & \\
\hline Service Quality & & & & & & & \\
\hline $\begin{array}{l}\text { Supplier } \\
\text { Attraction }\end{array}$ & 0.505 & 0.340 & 0.785 & & & & \\
\hline $\begin{array}{l}\text { Supplier } \\
\text { Commitment }\end{array}$ & 0.291 & -0.327 & -0.075 & 0.938 & & & \\
\hline $\begin{array}{l}\text { Supplier } \\
\text { Satisfaction }\end{array}$ & 0.723 & 0.434 & 0.562 & 0.436 & 0.839 & & \\
\hline Supplier Trust & 0.545 & -0.048 & 0.524 & 0.742 & 0.670 & 0.875 & \\
\hline $\begin{array}{l}\text { Time } \\
\text { Management } \\
\text { Quality }\end{array}$ & 0.690 & 0.336 & 0.487 & 0.526 & 0.825 & 0.725 & 0.919 \\
\hline
\end{tabular}

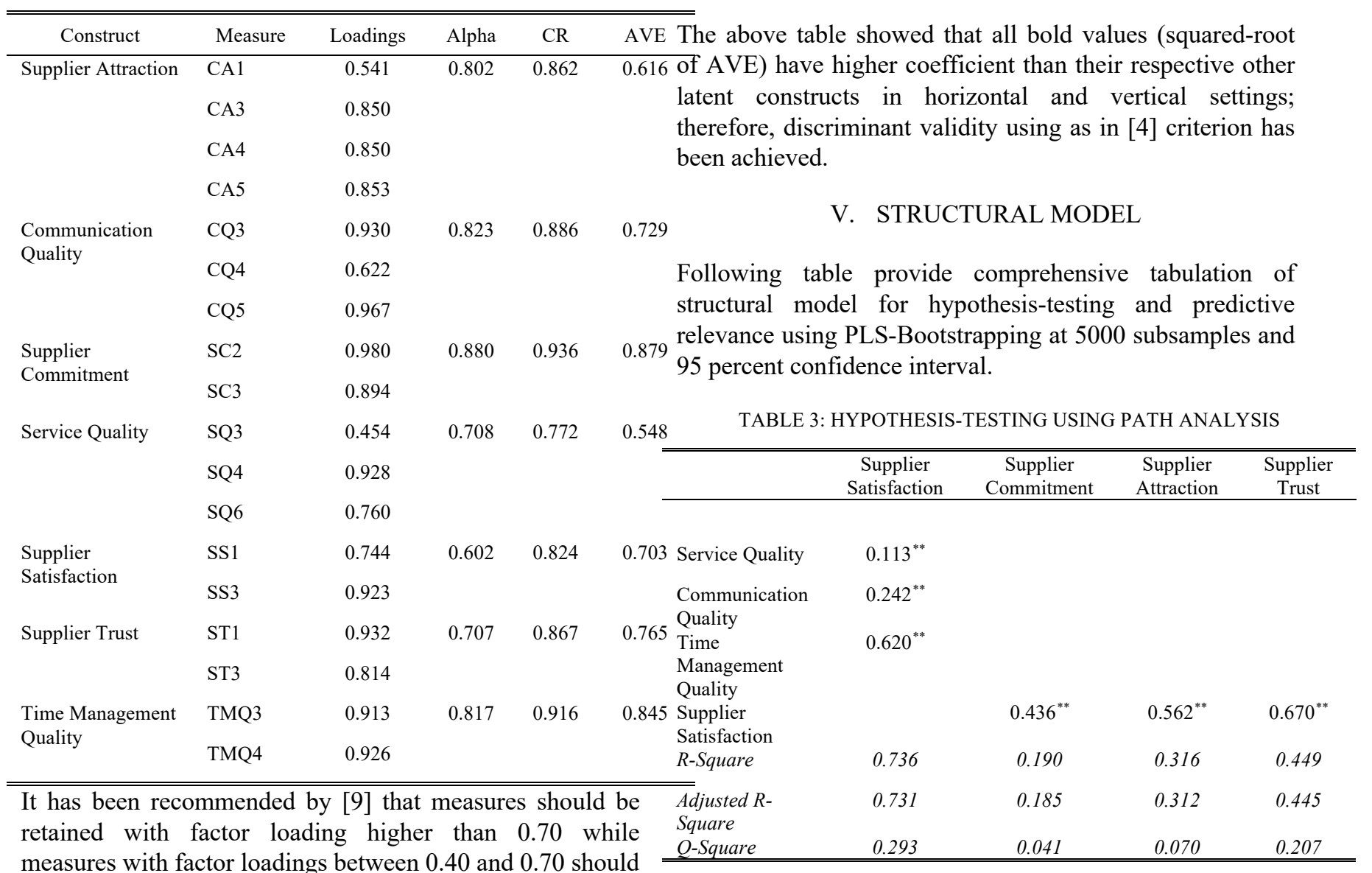
be retained on the basis of consild 0.50 ) and composite reliability (greater than 0.70 ) of the respective construct [10], [11], [12]. Henceforth, all measures of the latent constructs have factor loading higher than 0.70 except three measures i.e. SQ3 $(0.454)$ of service quality, CA1 (0.541) of supplier attraction, and CQ4 (0.622)

** These values are significant at statistical level of 0.05 or 5 percent.

The above table showed that $\mathrm{H} 1$ postulating significant relationship between service quality and supplier satisfaction was accepted $(0.113, \mathrm{p}<0.05)$; whereas the remaining two hypotheses i.e. $\mathrm{H} 2$ and $\mathrm{H} 3$ positing 
significant relationship of communication quality $(0.242, \mathrm{p}$ $<0.05)$ and time management quality $(0.620, \mathrm{p}<0.05)$ with supplier satisfaction were also accepted respectively. In addition, the latter three hypotheses i.e. H3, H4 and H5 have been accepted respectively providing that supplier satisfaction can improve supplier commitment $(0.436, \mathrm{p}<$ $0.05)$, supplier attraction $(0.562, \mathrm{p}<0.05)$ and supplier trust $(0.640, \mathrm{p}<0.05)$. The predictability power and relevance of all latent endogenous constructs was also found considerably acceptable in the light of substantial scholarly evidences as in [9], [10], [13], [12].

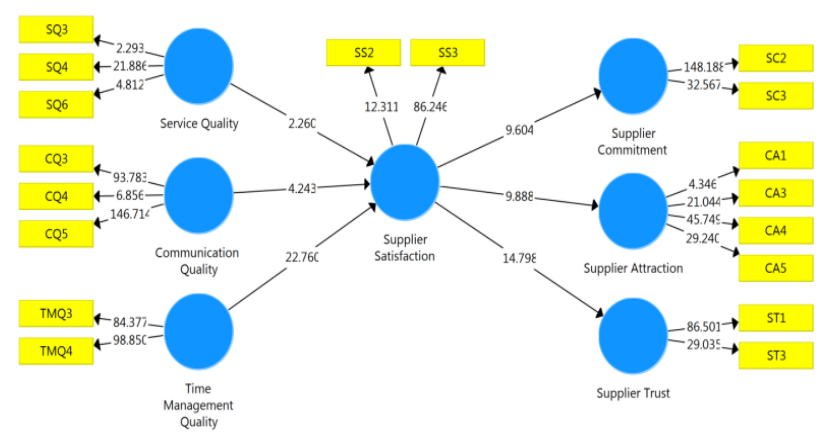

\section{CONCLUSION AND RECOMMENDATIONS}

The study established a significant and positive relationship between communication qualities with supplier satisfaction; service quality with supplier satisfaction; supplier satisfaction with supplier attraction, trust, commitment and time management quality with supplier. So, the outcomes of the research concludes that good communication is very necessary in every relationship so by decreasing the communication gap between the manufacturer and supplier it will automatically make manufacturer satisfied with the supplier and it results in a building clarity on both sides of the channel to eliminate hiccups or errors, such as wrong product lists or incomplete purchase orders. Also, service quality plays an important role in increasing the supplier satisfaction because when they are satisfied with the service or products they are providing to the customers it will automatically make them satisfied with their work and this satisfaction help the manufacturer in attracting more suppliers, and also in gaining their trust and commitment towards the organization so in order to gain the supplier trust and commitment manufacturer must produce high quality products or goods. Furthermore, it is also concluded that Good management of time allows a supplier to achieve or complete more task in a shorter period of time, reduces tension, and contributes to successful career and this will escalates the feeling of satisfaction among the supplier.

This study proposed many managerial recommendations. Firstly, it is recommended to establish a clear agenda at the very beginning of a new relationship for how to interact with suppliers. It means an effective business relationship results in less delays, more reliable supplies, less hurried shipping costs and, at most, less distractions for the practitioner. So, practitioners have to make sure the changes are attentive.
Secondly, in any relationship, the quickest way to create ill will is a lack of communication. Take the time to call the suppliers and inquire for exchange for the same form of outreach. This is especially important in terms of timelines. If a project timeline changes, one of the first people to know should be the supplier. The earlier notice puts them in the loop and could make it possible for a mutually agreed solution. Your supplier should be able to solve problems related to material quality and delivery, so use these features to your advantage when faced with difficulties.

Thirdly, there are normal everyday contingencies, such as late shipments or weather-ruined pallets that you should prepare for. Large disturbances are also expected, such as natural disasters or failure of vital equipment. Most of these contingencies are likely to be built in-house, but if the unthinkable happens, you can make a compromise for your suppliers to make sure they have a clear understanding of how you expect them to behave.

Furthermore, your supplier is doing a job and it should be compensated. Paying the vendors on time shows you trust them and their jobs. It will eventually increase their commitment and satisfaction level towards your organization.

Ask the vendors for feedback. Encourage them to have open discussions with you about how the partnership could work better or more effectively. Relationships with suppliers are collaborations and as such are also a two-way street.

Lastly, creating long-lasting, mutually beneficial partnerships with vendors can help you keep the production schedule on track and ensure that reliable products are produced and distributed. Such considerations are extremely important to ensure that your supplier partnerships are well handled and also help you in gaining supplier satisfaction, trust and commitment.

The present study has some recommendations for the future researchers. Such as it is suggested to increase the sample size as the current study is conducted on a small sample size. Further, it only targets the employees of Karachi, Pakistan so the outcomes cannot be generalized so employee of other cities can also be target. Moreover, some other variables like growth opportunity, reliability, profitability etc. can also be added in order to check the impact on buyer/supplier relationships satisfactions. Lastly, interviews can also be conduct by future researchers in order to get a broader picture on this topic.

\section{REFERENCES}

Busacca, B., \& Padula, G. Understanding the relationship between attribute performance and overall satisfaction: Theory, measurement and implications. Marketing Intelligence \& Planning, 23(6), 543-561, year 2005.

[2] Dalvi, M.V., \& Kant, R. Benefits, criteria and activities of supplier development: A categorical literature review. Asia Pacific Journal of Marketing and Logistics, 27(4), 653-675 year 2015.

[3] Fischer, M. Antecedents and benefits of supplier satisfaction and the influence of segmentation and status on buyer-supplier relationships: A multi-perspective case study of company $\mathrm{x}$ and four of its suppliers. University of Twente, year 2017. 

unobservable variables and measurement error: Algebra and statistics. Journal of marketing research, 18(3), 382-388, year 1981.

[5] Glas, A.H. The impact of procurement on supplier satisfaction: Service, communication, and speed. International Journal of Integrated Supply Management, 12(1-2), 90-117, year 2018.

[6] Gomm, R. Social research methodology: A critical introduction: Macmillan International Higher Education, year 2008 .

[7] Graziano, A.M., \& Raulin, M.L. Research methods: A process of inquiry: HarperCollins College Publishers, year 1993.

[8] Haenlein, M., \& Kaplan, A.M. A beginner's guide to partial least squares analysis. Understanding statistics, 3(4), 283-297, year 2004.

[9] Hair, J.F., Hult, G.T.M., Ringle, C., \& Sarstedt, M. A primer on partial least squares structural equation modeling (pls-sem): Sage Publications, year 2016.

[10] Hair, J.F., Ringle, C.M., \& Sarstedt, M. Pls-sem: Indeed a silver bullet. Journal of Marketing theory and Practice, 19(2), 139152, year 2011.

[11] Hair, J.F., Ringle, C.M., \& Sarstedt, M. Partial least squares structural equation modeling: Rigorous applications, better results and higher acceptance. Long range planning, 46(1-2), 112, year 2013 .

[12] Hair, J.F., Sarstedt, M., Hopkins, L., \& Kuppelwieser, V.G. Partial least squares structural equation modeling (pls-sem) an emerging tool in business research. European Business Review, 26(2), 106-121, year 2014.

[13] Hamali, S., Prihandoko, D., Kurniawan, S., \& Ramdhani, R. The effects of supply chain information integration on organizational performance in food small industry. Management Science Letters, 10(3), 695-702, year 2020.

[14] Hegenberg, J. A case study: Assessing the antecedents and benefits of supplier satisfaction. University of Twente, year 2017.

[15] Hughes, J.A., \& Sharrock, W.W. The philosophy of social research: Routledge, year 2016.

[16] Huttinger, L. Preferential customer treatment by suppliers: Identifying benefits and antecedents, year 2014.

[17] Koenders, S. Supplier satisfaction: The importance of achieving excellence as a buying company to create satisfied suppliers. University of Twente, year 2016.

[18] Kothari, C.R. Research methodology: Methods and techniques: New Age International, year 2004.

[19] Koul, L. Methodology of educational research: Vikas publishing house PVT Ltd, year 2009.

[20] Kumar, S., \& Phrommathed, P. Research methodology: Springer, year 2005.

[21] Leedy, P., \& Ormrod, J. What is research. practical research: planning and design, year 2010.

[22] Leenders, M.R., Nollet, J., \& Ellram, L.M. Adapting purchasing to supply chain management. International Journal of Physical Distribution \& Logistics Management, 24(1), 40-42, year 1994.

[23] Mackey, A., \& Gass, S.M. Second language research: Methodology and design: Routledge, year 2015.

[24] Makkonen, H., Vuori, M., \& Puranen, M. Buyer attractiveness as a catalyst for buyer-supplier relationshipdevelopment. Industrial Marketing Management, 55, 156-168, year 2016.

[25] Malhotra, N., \& Birks, D. Marketing research: An applied perspective. Harlow: Prentice Hall, year 2006.

[26] Meena, P.L., Sarmah, S.P., \& Sinha, S. Measuring satisfaction in buyer-supplier relationship from suppliers perspective. International Journal of Business Performance and Supply Chain Modelling, 4(1), 60-74, year 2012.

[27] Miao, Y., Du, R., Li, J., \& Westland, J.C. A two-sided matching model in the context of $\mathrm{b} 2 \mathrm{~b}$ export cross-border ecommerce. Electronic Commerce Research, 19(4), 841-861, year 2019.

[28] Patrucco, A.S., Luzzini, D., Moretto, A., \& Ronchi, S. Attraction in buyer-supplier relationships: Improving supply network performance through purchasing recognition and proficient collaboration initiatives. Business Process Management Journal, 25(2), 347-367, year 2019

[29] Paul, W.T., Semeijn, J., \& Ernstson, S. Supplier satisfaction and commitment: The role of influence strategies and supplier development. Journal of purchasing and supply management, 16(1), 17-26, year 2010
[30] Pulles, N.J., Schiele, H., Veldman, J., \& Hüttinger, L. The impact of customer attractiveness and supplier satisfaction on becoming a preferred customer. Industrial marketing management, 54, 129-140, year 2016

[31] Schiele, H., Ellis, S.C., Eßig, M., Henke, J.W., \& Kull, T.J. Managing supplier satisfaction: Social capital and resource dependence frameworks. Australasian Marketing Journal (AMJ), 23(2), 132-138, year 2015.

[32] Shanka, M.S., \& Buvik, A. When does relational exchange matters? Social bond, trust and satisfaction. Journal of Business-to-Business Marketing, 26(1), 57-74, year 2019

[33] Shub, A.N., \& Stonebraker, P.W. The human impact on supply chains: Evaluating the importance of "soft" areas on integration and performance. Supply Chain Management: An International Journal, 14(1), 31-40, year 2009

[34] Tanskanen, K., \& Aminoff, A. Buyer and supplier attractiveness in a strategic relationship - a dyadic multiplecase study. Industrial Marketing Management, 50, 128-141, year 2015 .

[35] Tchokogué, A., Nollet, J., \& Robineau, J. Supply's strategic contribution: An empirical reality. Journal of Purchasing and Supply Management, 23(2), 105-122, year 2017.

[36] Tormöhlen, F. Improving a buyer's standing at its supplier: An investigation of relationship changing episodes. University of Twente, year 2019.

[37] Veen, I. The effect of different types of trust and commitment on supplier satisfaction. University of Twente, year 2018.

[38] Wong, C., Skipworth, H., Godsell, J., \& Achimugu, N. Towards a theory of supply chain alignment enablers: A systematic literature review. Supply Chain Management: An International Journal, 17(4), 419-437, year 2012. 